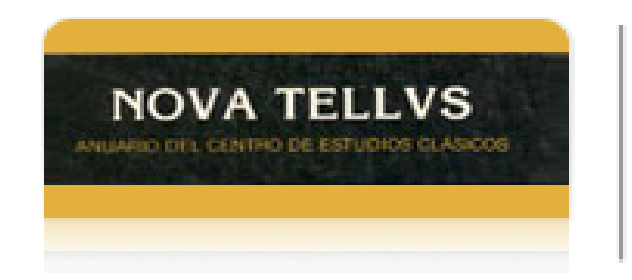

Nova Tellus

ISSN: 0185-3058

novatelu@servidor.unam.mx

Centro de Estudios Clásicos

México

Montemayor Aceves, Martha Elena

Leyes contra el crimen de magia (crimen magiae): la Apología de Apuleyo

Nova Tellus, vol. 26, núm. 2, 2008, pp. 201-222

Centro de Estudios Clásicos

Distrito Federal, México

Disponible en: http://www.redalyc.org/articulo.oa?id=59115497009

- Cómo citar el artículo

- Número completo

- Más información del artículo

Página de la revista en redalyc.org

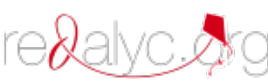

Sistema de Información Científica

Red de Revistas Científicas de América Latina, el Caribe, España y Portugal

Proyecto académico sin fines de lucro, desarrollado bajo la iniciativa de acceso abierto 


\title{
Leyes contra el crimen de magia (crimen magiae): la Apología de Apuleyo
}

\author{
Martha Elena MONTEMAYOR ACEVES \\ Universidad Nacional Autónoma de México \\ montemayor.martha@gmail.com
}

RESUMEN: Dado que el crimen es un acto ilícito que ofende a la comunidad y afecta la seguridad de la república romana, da lugar a un juicio público que interesa a la colectividad. En Sabratha, aproximadamente en el año 158 d. C., se tiene noticia de un juicio público por una acusación de magia (crimen magiae). El acusado, Apuleyo, se defiende personalmente de una manera magistral, en un discurso en el que nos permite conocer costumbres y prácticas de una provincia romana. En este artículo, se pretende analizar los aspectos jurídicos que envuelven a una acusación de tal naturaleza, así como las penas a las que eran sometidos los reos de este crimen, de acuerdo con la lex Cornelia de sicariis et veneficiis, a la lex duodecim tabularum y a algunas constituciones imperiales.

$$
* * *
$$

ABSTRACT: Crime being an illicit action that offends the whole community and means a security risk for the Roman Republic, it calls for a public trial involving every member of that community. In Sabratha (Libya), around the year 158 A.D., we hear from a public trial to a man under the accusation of performing magic (crimen magiae). The man under trial, Apuleius, carries out a brilliant defense by making a plea that allows us to get acquainted with legal customs and practices in a Roman province. The purpose of this article is, then, to analyze the legal aspects involved in such an accusation, as well as the punishments inflicted on people found guilty of such a crime. As we will show, these penalties were established according to several laws: lex Cornelia de sicariis et veneficiis, lex duodecim tabularum, as well as some imperial constitutions.

PALABRAS CLAVE: Apuleyo, derecho romano, ley Cornelia, ley de las XII Tablas, magia.

RECEPCIÓN: 22 de septiembre de 2008.

ACEPTACIÓN: 31 de octubre de 2008.

NOVA TELLVS, $26 \cdot 2,2008$ 


\title{
Leyes contra el crimen de magia (crimen magiae): la Apología de Apuleyo
}

\author{
Martha Elena Montemayor ACEVES
}

Apuleyo fue un escritor latino, que nació en la ciudad de Madaura, Argelia, provincia romana de África, entre los años 125 y 128 d. C. Fue estudioso de varias disciplinas: ciencias naturales, medicina, filosofía, música, gramática, retórica y derecho; así como seguidor de varias religiones, iniciándose en los Misterios de Eleusis y en los de Isis. ${ }^{1}$ Debido a su profesión de abogado y a sus conocimientos de derecho, en su obra literaria se pueden apreciar numerosos asuntos y situaciones jurídicas que, combinados con la lengua latina, resultan en verdad interesantes tanto para el filólogo como para el jurista.

En su obra Apologia pro se de Magia, ${ }^{2}$ Apuleyo nos dejó noticia de que en Sábrata, cerca de la ciudad de Oea, ${ }^{3}$ aproximadamente en el año 158 d. C., se enfrentó a un juicio por una acusación de magia, a la que se refiere como crimen magiae. ${ }^{4}$ El término jurídico crimen $^{5}$ se usa para indicar una acusación

\footnotetext{
${ }^{1}$ Cf. Apol., 55; Met., XI.

${ }^{2}$ Apología o Discurso sobre la magia en defensa propia, traducción de Roberto Heredia.

${ }^{3}$ Oea, Sábrata y Leptis Magna componían la región de las tres ciudades, llamadas todas en conjunto Trípoli, en Libia. Apuleyo viajaba de Cartago a Alejandría y se detuvo en Oea a descansar.

${ }^{4}$ Cf. Apol., 25, 81.

${ }^{5}$ Los actos ilícitos que lesionan a un particular en su persona, en su familia o en su patrimonio son los llamados delicta, que dan lugar a un juicio privado que se inicia a petición de la víctima. El delito se castiga con una pena, que consiste en una cantidad de dinero; aunque según D’Ors: "la distinción terminológica entre delictum y crimen no es muy rigurosa, se trata de términos del lenguaje corriente

NOVA TELLVS, 26•2, 2008
} 
por causa de un acto ilícito que atenta contra el orden establecido, ofende a la comunidad, es perseguido en nombre de ésta $\mathrm{y}$, por tanto, da lugar a un juicio público, en un tribunal permanente, bajo la dirección de un magistrado.

El juicio público al que se enfrentó Apuleyo, se realizó de acuerdo con el procedimiento cognitorio, ${ }^{6}$ fungió como juez, asistido por un consejo, el procónsul Claudio Máximo, el gobernador de la provincia romana de Sábrata, a quien Apuleyo, en su discurso pronunciado durante el juicio, se dirige así: "Es bueno, Máximo, que la causa se lleve ante ti" (Bene quod apud te, Maxime, causa agitur); ${ }^{7}$ se encontraban presentes los acusadores, los testigos de ambas partes y también los habitantes de Oea; un secretario del tribunal tomaba nota de todo lo que se decía; había un reloj de agua, una clepsidra, lo que sabemos por frases como: "detén el agua" (aquam sustine) $)^{8} \mathrm{o}$ "deja que fluya el agua" (aquam sinas fluere). ${ }^{9}$ Apuleyo llevó su propia causa, es decir, actuó como abogado en su propio juicio para defenderse a sí mismo.

En este trabajo, pretendo analizar, por un lado, el crimen magiae desde el punto de vista jurídico, señalando las leyes que lo castigaban; por otro, intento descubrir algunas de las

que los juristas utilizan en un sentido u otro tan sólo preferentemente”. Cf. D’Ors, $\S 360$.

${ }^{6}$ La cognitio extra ordinem es el procedimiento civil romano desarrollado en época imperial, sobre todo en provincias. Se lleva a cabo ante el magistrado, quien funge como juez. Su sentencia puede ser apelada ante un magistrado mayor, incluso el mismo Emperador. Cf. Padilla, § 93.

${ }^{7}$ Apol., 36. Para las citas del texto latino, me basé en la edición de Les Belles Lettres.

${ }^{8}$ Apol., 37.

${ }^{9}$ Apol., 94. Este reloj era en realidad un cronómetro, pues no marcaba la hora, sino el tiempo que era asignado a los oradores en el tribunal. Apuleyo lo describe en Met., III, 3, 1: “...una vez que, para medir el tiempo del discurso, se vierte agua en un vasito perforado delicadamente, a manera de embudo, por el que fluye el agua gota a gota... (ad dicendi spatium vasculo quoidam in vicem col[l]i graciliter fistulato ac per hoc guttatim defluo infusa aqua...). 
posibles prácticas en torno a la magia, que llevaron a Apuleyo a defenderse de tal acusación.

Desde el principio del discurso, el autor presenta la acusación, se dirige al procónsul Claudio Máximo:

Sicinio Emiliano, anciano de temeridad muy notoria, trataría de completar mi acusación (accusationem mei... impleturum)... hace cinco o seis días, cuando llevaba una causa (causam agere) de mi esposa Pudentila contra los Granios... los abogados de Emiliano (patroni eius) me atacaron con maledicencias (incessere maledictis) y empezaron a acusarme de maleficios mágicos (insimulare magicorum maleficiorum)... los desafié para que presentaran una acusación formal (ultro eos ad accusandum)... se le obligó <a Emilano> a firmar (ad subscribendum compellitur)... entonces eligió para acusarme la calumnia de magia (calumniam magiae... delegit ad accusandum)... la cual más fácilmente es infamante que probada... al día siguiente entregó un libelo (libellum) a nombre de mi hijastro Sicinio Pudente, que es todavía un niño, y se adscribe como su asistente. ${ }^{10}$

Sicinio Emiliano era el excuñado de Pudentila, hermano de su primer esposo ya muerto. Pudentila era una viuda, de 40 años de edad, madre de dos hijos, Ponciano y Pudente. Apuleyo cuenta que Sicinio Emiliano lo atacó, con sus abogados, primero con palabras (maledicta), o sea, difamándolo, incurriendo en el delito de injuria; ${ }^{11}$ después lo acusó, también de palabra, de "maleficios mágicos", "de magia" y de que mediante encantamientos y brebajes enamoró a Pudentila.

Ante esta actitud que mostró públicamente, fue obligado $<$ Emiliano $>$ a presentar formalmente con todo y firma, la acusación, la cual hizo en un libelo, ${ }^{12}$ de acuerdo con el procedimien-

\footnotetext{
${ }^{10}$ Apol., 1 y 2.

${ }^{11}$ En sentido general, iniuria significa lo que no se hace de acuerdo a derecho (quod non iure fit). En sentido específico, indica un delito que se comete cuando se lesiona el honor de una persona libre con golpes o con palabras. La pena es pecuniaria. Cf. PS. en Coll., 2, 5, 4.

${ }^{12} \mathrm{Se}$ trata del libellus conventionis, escrito mediante el cual el demandante ejercita la acción.
} 
to cognitorio de la época imperial. ${ }^{13}$ Como una acusación de tal naturaleza era difícil de probar, Emiliano puso, en el libelo, el nombre de su sobrino Pudente, de 15 años de edad, como si fuera el acusador, y no el suyo propio, de esta manera se protegía en caso de que se demostrara que había acusado falsamente. La Lex Remnia de calumniatoribus, del 80 a. C., según el jurista Marciano,

es la que impone una pena a los calumniadores... pero no se considera que comete calumnia el que no prueba lo que al punto sostuvo (sed non qui non probat quod intendit protinus calumniari videtur), pues se encomienda la averiguación de ese asunto al arbitrio del juez (nam eius rei inquisitio arbitrio cognoscentis committitur)... pero si <el juez> lo sorprende en evidente calumnia (si vero in evidenti calumnia eum deprehenderit), le impone la pena legítima... y aunque nada hubiera concretado acerca de la pena, sin embargo se ejercitará contra él el poder de la ley (legis potestas adversus eum exercebitur). ${ }^{14}$

La pena a la que se refiere Marciano podía ser pecuniaria en caso de que el falso acusador hubiera recibido dinero, pero en el caso de Emiliano la pena era "la pérdida de los derechos honoríficos correspondientes a los ciudadanos... le privaba el magistrado del derecho de optar a los cargos públicos, del de emitir sufragio, del de petición y del de representar judicialmente a otro..." ${ }^{15}$ Un menor de 17 años estaba exento de tal responsabilidad, por eso Emiliano se presenta como su simple asistente.

Pudentila era una mujer rica, su fortuna consistía en 4 millones de sestercios, además de, entre otras propiedades, granjas, rebaños, predios, campos, una casa muy grande y opulenta. Ella como mulier libera, y además sui iuris, le prometió a

\footnotetext{
${ }^{13}$ Ver nota 6.

${ }^{14}$ D., 48, 16, 2-4.

${ }^{15}$ Mommsen, p. 312. Estas restricciones eran impuestas al tachado con la nota de infamia. Cf. D., 3, 2.
} 
Apuleyo, su segundo esposo, mediante la figura de la promissio dotis, ${ }^{16}$ la cantidad de 300 mil sestercios por concepto de dote. La razón de la acusación de magia (crimen magiae) era, a los ojos de Apuleyo, muy clara: "para cualquiera es claro que ninguna otra cosa sino la envidia fue lo que provocó a este individuo (cuivis clare dilucet aliam rem invidia nullam esse quae hunc... provocarit)", ${ }^{17}$ en realidad Emiliano quería que la fortuna quedara en sus manos y no en las de un extraño a la familia.

Apuleyo, al abordar el tema sobre la magia, distingue dos tipos: la magia buena, la que podríamos llamar blanca; y la mala, la que hace daño, o sea, la llamada comúnmente negra.

La magia blanca, primeramente, la refiere a lo que pensaban y consideraban los persas:

mago es en la lengua de los persas lo que en la nuestra sacerdote (sacerdos), ¿qué culpa hay en ser sacerdote, en conocer, saber y dominar las leyes de las ceremonias (nosse atque scire atque callere leges caerimoniarum), la ley divina de los sacrificios (fas sacrorum), el derecho de las religiones (ius religionum)?... Magia es lo que Platón entiende cuando recuerda qué disciplinas inculcan los persas al niño destinado a reinar: 'cuando llega a los catorce años, reciben al muchacho... pedagogos reales. Son escogidos, en número de cuatro, entre los... que gozan de mejor fama: el más sabio, el más justo, el más prudente y el más vale-

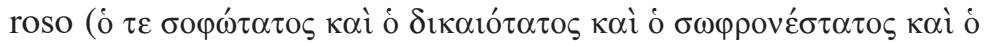

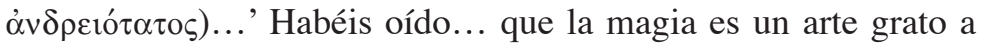
los dioses inmortales (magian artem esse dis immortalibus acceptam)..., es piadosa y conocedora de la divinidad... El mismo Platón... dejó escrito lo siguiente: 'los encantamientos son las

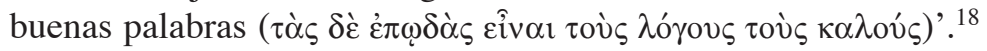

${ }^{16}$ La promissio dotis es la promesa de dote hecha en forma de stipulatio: el constituyente hace la promesa, el aceptante expresa su conformidad. Cf. Padilla, $\S 61,3$.

17 Apol., 67.

${ }^{18}$ Apol., 25, 26. 
En estos pasajes, el autor trata de situar a la magia en el mismo nivel que la religión y la filosofía, la que radica en el conocimiento, la que todo filósofo o científico, dos de sus múltiples cualidades, tiene necesidad de conocer, la que es propia de los sacerdotes. ${ }^{19}$

La magia mala, la que produce daño, es la que se castiga con las leyes, se refiere a ella de la siguiente manera:

según la costumbre vulgar éstos ${ }^{20}$ consideran mago al que por su comunicación de palabra con los dioses inmortales es capaz de hacer (polleat) todo lo que quiere con la increíble fuerza de conjuros (cantaminum)... Me admiro de que ustedes no hayan temido acusar a quien según confiesan, puede tanto... quien cita a juicio a un asesino (sicarium qui in iudicium vocat), llega acompañado (comitatus venit); quien acusa a un envenenador (qui venenarium accusat), come más escrupulosamente (scrupulosius cibatur); quien denuncia a un ladrón (qui furem arguit), cuida sus bienes (sua custodit); pero quien lleva a un mago a un juicio que se castiga con la pena capital (enimvero qui magum in discrimen capitalis deducit)... ¿con qué... evitará una desgracia invisible e inevitable? (quibus... perniciem caecam et inevitabilem prohibeat?). ${ }^{21}$

En este pasaje, Apuleyo está haciendo una clara alusión a la lex Cornelia de sicariis et veneficiis, la cual castigaba tanto el homicidio consumado como la intención, fue propuesta por Sila en el año 81 a. C., y distinguía diferentes tipos de delincuentes: el asesino, el envenenador y el ladrón.

Marciano dice:

Es obligado por la ley Cornelia de los asesinos y envenenadores el que haya dado muerte a un hombre (qui hominem occiderit) ...

\footnotetext{
${ }^{19} \mathrm{Cf}$. Ma. José Hidalgo, quien hace un interesante estudio sobre teurgia, la magia negra, en su artículo "Sociedad e ideología en la obra de Apuleyo de Madaura".

${ }^{20}$ Se refiere a sus acusadores Sicinio Emiliano y Herenio Rufino. Este último era el consuegro de Pudentila, suegro de su hijo Ponciano, quien en el momento del juicio ya había muerto.

${ }^{21}$ Apol., 26.
} 
o el que haya andado con un arma para cometer un hurto (quive furti faciendi causa cum telo ambulaverit)... el que haya hecho o suministrado un veneno para matar a un hombre (qui hominis necandi causa venenum confecerit dederit)... ${ }^{22}$

La pena de esta ley se aplica al que haya vendido al público medicamentos malos (medicamenta mala) o lo haya hecho para matar a un hombre. El que se añada 'malo' (malum) a la palabra 'veneno' (venenum) muestra que hay también algunos venenos que no son malos. Es pues una palabra intermedia que significa tanto lo que se prepara para curar como lo que se prepara para matar (ad sanandum... ad occidendum), pero también lo que se llama filtro de amor (amatorium)... Por otro senadoconsulto se estableció que fueran obligados con la pena de esta ley los comerciantes de afeites (pigmentarii), si dieron temerariamente a alguien cicuta (cicutam), salamandra (salamandram), acónito (aconitum), polilla de pino (pituocampas) o bupresto (bubrostim), mandrágora (mandragoram), cantárida (cantharidas) y lo que se haya dado como afrodisíaco (lustramenti causa). ${ }^{23}$

Es importante notar que esta fuente jurídica no menciona la palabra magia ni magus, más bien se refiere a la persona que prepara venenos, los cuales ocasionarían la muerte, o provocarían hechizos como el amatorium, el filtro de amor, o el lustramentum, el afrodisíaco. Así pues, el magus estaría relacionado con el venenarius, y como el "veneno" sirve tanto para curar como para matar, se está haciendo una gran diferencia entre ciencia y magia, la primera sirve para hacer el bien, y la segunda para hacer el mal; por lo tanto, lo que hace daño es lo penado por la ley. "Es probable que - según Mommsen - en tiempos de la república, bajo el influjo de las creencias populares..., la magia fuese considerada como una especie de envenenamiento". ${ }^{24}$

${ }^{22}$ D., 48, 8, 1 pr.-1.

${ }^{23} D$., 48, 8, 3, 1-3. El acónito y la mandrágora son plantas, la cantárida y el bupresto, insectos. Se refiere a preparar venenos tal vez en polvo, en aceite o líquidos para beber.

${ }^{24}$ Mommsen, p. 404. 
La pena de la lex Cornelia de sicariis et veneficiis, en la época imperial, se da de acuerdo con la clase social y está especificada por el mismo Marciano:

la pena de la ley Cornelia de asesinos y envenenadores es la deportación a una isla y la confiscación de todos sus bienes (omnium bonorum ademptio)... los de clase humilde suelen ser arrojados a las fieras (humiliores solent bestiis subici), pero los de clase alta son deportados a una isla (altiores vero deportantur in insulam). ${ }^{25}$

\section{Modestino aclara:}

Los que cometieron una muerte voluntariamente con dolo malo suelen ser deportados (deportari) si tienen algún cargo (in honore aliquo positi), quienes están en grado inferior (qui secundo gradu sunt) son castigados con la pena de muerte (capite)... ${ }^{26}$

\section{En las Sentencias de Paulo se lee:}

La ley Cornelia inflige la pena de la deportación (poenam deportationis infligit)... a quien por matar a un hombre haya tenido, vendido o preparado un veneno (qui venenum hominis necandi causa habuerit vendiderit paraverit)... Se dispuso que todas estas fechorías <se está hablando del asesino, del ladrón y del envenenador $>$ se castigaran con la pena capital para los de clase alta (in honestiores poena capitis vindicari); pero los de clase humilde o se les crucifica o se les expone a las bestias (humiliores vero aut in crucem tolluntur aut bestiis subiciuntur). ${ }^{27}$

\footnotetext{
${ }^{25}$ D., 48, 8, 3, 5 .

${ }^{26}$ D., 48, 8, 16.

${ }^{27}$ PS., 5, 23, 1; Coll., 1, 2, 1. Acerca de la poena capitis Ulpiano señala: "Debemos entender al condenado de un asunto capital así: al condenado por alguna causa le corresponde o la muerte, o la pérdida de la ciudadanía, o la esclavitud (Rei capitalis damnatum sic accipere debemus, ex qua causa damnato vel mors vel etiam civitatis amissio vel servitus contingit)". Cf. D., 48, 19, 2 pr. Por otra parte, Modestino define: "La palabra 'capital' ha de entenderse como pena de muerte o pér-
} 
En otro pasaje de las mismas Sentencias:

los de clase humilde son condenados a los juegos públicos o a la mina (humiliores in ludum aut in metallum damnantur), y los de clase alta, castigados con la confiscación de la mitad de sus bienes, son relegados (honestiores dimidia parte bonorum multati relegantur). ${ }^{28}$

Siguiendo estas fuentes jurídicas, Pauli Sententiae, Digesta y Collatio, ${ }^{29}$ podemos conocer las diferentes penas: para los de clase humilde, exposición a las bestias, juegos públicos gladiatorios, crucifixión o trabajos en las minas; para los de clase alta, deportación a una isla y confiscación de todos sus bienes o de la mitad, perdían además la ciudadanía y el retorno ilícito era castigado con la muerte.

Apuleyo era de familia acomodada, su padre había desempeñado el cargo de duumvir, la más alta magistratura de las ciudades provinciales que correspondía a la de los cónsules en Roma; dejó a sus dos hijos dos millones de sestercios, es decir, él heredó un millón. ${ }^{30}$ De acuerdo con este dato, podríamos deducir que no pertenecía a la clase social de los humiliores, y la pena que le hubiera correspondido, de haber sido encontrado culpable del crimen de magia y juzgado de acuerdo con la ley Cornelia de sicariis et veneficiis, sería la deportación a una isla, la confiscación de la mitad o de la totalidad de sus bienes y la pérdida de la ciudadanía romana. Todo esto era un castigo denigrante, el culpable de un crimen que atentaba contra la paz y la convivencia del pueblo era afectado en su fama y honor; además, según Marciano:

dida de la ciudadanía (appellatio capitalis mortis vel amissionis civitatis intellegenda est)". Cf. D., 50, 16, 103.

${ }^{28}$ PS., 5, 23, 4; D., 48, 8, 17; Coll., 1, 7, 2. Los honestiores conformaban la categoría de personas de rango elevado, integrada por los senadores, caballeros y decuriones, que desde la época del principado se distinguía de la clase de los humiliores. Cf. D., 1, 18, 6, 2; 47, 11, 6; 48, 8, 3.

${ }^{29}$ Ver Comparación en la "Bibliografía".

${ }^{30}$ Cf. Apol., 23. 
la pena perduraba incluso después de su muerte (poena etiam post mortem manet), y no se permitía trasladarlo de ahí a otro lugar para enterrarlo (nec licet eum inde transferre aliubi et sepelire), si no era con el permiso del príncipe. ${ }^{31}$

Apuleyo continúa hablando de la magia negra:

Esa magia, por cuanto yo sé, es un asunto encomendado a las leyes, prohibido ya desde antiguo por las XII Tablas a causa de los increíbles encantamientos de las cosechas (propter incredundas frugum illecebras); así pues, es oculta, no menos que repugnante y horrible, y por lo común se practica en las noches, se esconde en las tinieblas, rehúye testigos y murmura conjuros (carminibus); a ella se admiten pocos individuos no sólo de entre esclavos sino también de entre libres. ${ }^{32}$

El mago opera por cuenta propia y lo hace en privado y a ocultas para beneficios privados en oposición al bien público. El hecho de que la magia fuera individual y no colectiva, como lo eran la mayoría de las religiones, convencía a la gente de que era ilegal e impía.

La ley de las XII Tablas a la que alude es la VII, 8, la cual dice textualmente: "El que hubiera atraído con encantamiento las cosechas (Qui fruges excantassit)". ${ }^{33}$ Según Rives, esta ley se refiere a la influencia que ejerce la magia mala sobre las cosechas, significa 'quitar a través de encantamientos', es decir, quitar o remover las cosechas por otra persona diferente del dueño mediante conjuros o cantos mágicos (carmina), como una transferencia mágica de las cosechas del campo de una persona al de otra. ${ }^{34}$ En la expresión propter incredundas fru-

\footnotetext{
${ }^{31}$ Cf. D., 48, 24, 2.

${ }^{32}$ Apol., 47. La ley de las XII tablas fue la primera legislación romana escrita por los decemviri en doce tablas de madera, primero, y después de bronce, las cuales se expusieron en el foro, fueron destruidas por los galos en 387 a. C. Se conoce por citas y referencias de autores de finales de la República e inicio del Imperio.

${ }^{33}$ Esta ley se conoce por Plinio en Hist. Nat., 28, 17.

${ }^{34}$ Rives, J. B., "Magic in the XII Tables Revisited", p. 274.
} 
gum illecebras, Apuleyo utiliza la misma palabra que la ley de las XII Tablas frux, frugis; y el sustantivo illecebra, ae, en vez del verbo excantassit, pero todo esto con el mismo significado: 'encantamiento de las mieses'.

Otra ley de las XII Tablas sobre el mismo asunto es la VIII, 1a.: "El que hubiera formulado un conjuro (Qui malum carmen incantassit)"; 35 y la VIII, 1b.:

Las doce tablas, como castigaran pocas cosas con la pena capital, consideraron que se debía aplicar también esta pena en estos casos (XII tabulae cum perpaucas res capite sanxissent, in his hanc quoque sanciendam putaverunt), si alguien injuriara o compusiera un canto mágico, que produjera infamia o deshonra a otro (si quis occentavisset sive carmen condidisset, quod infamiam faceret flagitiumve alteri). ${ }^{36}$

Esta ley, relacionada con el carmen incantassit, se ha entendido también en otro sentido. En Pauli Sententiae, 5, 4, 6, se menciona dentro de la acción de injuria, como poemas o cantos difamatorios (de famosis carminibus), es decir, como daño personal en forma de difamación. De la misma manera lo interpretó Cicerón, pues la menciona en el contexto de los poetas cómicos que ofenden con sus versos a personajes famosos. San Agustín ${ }^{37}$ cita a Cicerón en el mismo sentido.

La legislación de las XII Tablas era muy severa y en la tabla VIII, 9, se ordena que

el púber que por las noches pastara o segara mieses ajenas era muerto y ahorcado en honor a Ceres (suspensumque Cereri necari); el impúber, de acuerdo con el arbitrio del pretor, era azotado (praetoris arbitratu verberari), y entregado en noxa <para reparar el daño $>\mathrm{u}$ obligado a pagar el doble (noxiamve duplionemve decerni). ${ }^{38}$

\footnotetext{
${ }^{35}$ Esta ley se conserva por Plinio en Hist. Nat., 28, 17.

${ }^{36}$ Esta ley se conserva por Cicerón en De Rep., 4, 10, 12.

${ }^{37}$ San Agustín, De Civ. Dei, 2, 9.

${ }^{38}$ Esta ley se conserva por Plinio en Hist. Nat., 18, 12.
} 
En la tabla VIII, 10, se señala que

quien hubiera incendiado un montón de trigo (acervum frumenti)... era muerto en el fuego atado y azotado (vinctus verberatus igni necari)... si lo hubiera hecho consciente y premeditadamente (si modo sciens prudensque id commiserit). ${ }^{39}$

Es probable que la base de la acusación de magia esté en la misma ley de las XII Tablas, pues así como se hacían hechizos para atraer cosechas ajenas, del mismo modo Apuleyo pudo haber realizado hechizos para atraer a Pudentila. Tal vez es la razón por la que el autor cita dicha ley, además de que, como todo ciudadano romano, es fiel a la tradición aludiendo al pensamiento de los antiguos. Aunque la ley de las XII Tablas nunca se derogó, no se aplicaban literalmente las penas establecidas en ellas, sirvió de modelo para los juristas, quienes crearon leyes más abiertas y flexibles.

La principal acusación, como ya se señaló, es la de haber hechizado a Pudentila, sus enemigos tratan de probarla con otras acusaciones encaminadas a demostrar que él es un mago. En diversos pasajes Apuleyo las enumera, expongo algunas:

Mi acusador ha dicho ¿por qué has buscado peces de ciertos géneros?... ¿Por qué se casó contigo una mujer libre después de 13 años de viudez?... Apuleyo tiene en casa algo que venera religiosamente... Un muchacho llamado Talo se cayó <como desmayado $>$ en su presencia ${ }^{40} \ldots$ Destazaste un $\operatorname{pez}^{41}$... Habéis dicho que me fue traída una mujer libre, afectada por la misma enfermedad de Talo, que prometí curarla y también se desplomó, encantada por $\mathrm{mi}^{42} \ldots$ Que yo solía celebrar sacrificios nocturnos. ${ }^{43}$

\footnotetext{
${ }^{39}$ Esta ley se conserva por Gayo en D., 47, 9. 9.

${ }^{40}$ Apol., 27.

${ }^{41}$ Apol., 41.

42 Apol., 48.

${ }^{43}$ Apol., 57.
} 
Trataré de explicar someramente cada una de estas cuatro acusaciones y la manera en que se defiende.

Primera: “¿por qué has buscado peces de ciertos géneros?” Los magos estudian propiedades de los seres vivos, por eso lo acusan de que destaza peces para su estudio y no para comérselos. Él pregunta:

¿Pues qué tiene de extraño... que busque en los peces algunos remedios?... ¿Acaso... conocer y conseguir los remedios es más propio de un mago que de un médico, o finalmente de un filósofo, quien ha de usarlos no para lucrar sino para ayudar? Los antiguos médicos conocían también ciertamente algunos encantamientos (carmina) como remedio de las heridas... Nada, pues, de lo que se hace para restaurar la salud es reprobable. ${ }^{44}$

Apuleyo está haciendo una importante distinción entre médico y mago; es decir, él también es un médico y todo lo que se hace para el bien de los demás está, por supuesto, permitido; en cambio, lo que se hace para causar daño es prohibido por las leyes. Por eso, gran parte de su defensa consiste en que él es estudioso de la ciencia. Le explica al procónsul Máximo que ha escrito libros sobre peces, que muchos de sus nombres los ha tomado de la lengua griega y los ha hecho derivar a la lengua latina, los juegos de palabras podían tener virtudes mágicas y se burla pronunciando diferentes nombres de peces, para que piensen que está recitando conjuros y, en realidad, son términos aristotélicos: "selacios, malacios, malcostráceos, condracanta, ostracoderma, carcarodonta, lepidotos, folidotos...". 45

Segunda: "¿por qué se casó contigo una mujer libre después de 13 años de viudez?" Esta acusación está relacionada con Talo, un esclavo que se desmayó en su presencia, y con la mujer libre que igualmente se desmayó. La acusación consis-

\footnotetext{
${ }^{44}$ Apol., 40. La traducción de los pasajes referidos en las notas 40 a 52 es de Roberto Heredia.

45 Apol., 38.
} 
tía en que mediante hechizos y brebajes encantaba a las personas. Se defiende explicando que Talo, a quien habían llevado a su presencia para que lo curara, tenía epilepsia, por lo tanto, no se desmayó por sus encantamientos, "necesita - dice Apuleyo - más bien de un médico que de un mago (medico potius quam mago), por la epilepsia se desploma tres o cuatro veces al día... su rostro está cubierto de llagas, golpeada su frente y su nuca". ${ }^{46}$ De igual manera se le llevó

a una mujer enferma para que la sanara... que mis acusadores declaren que curar las enfermedades es propio de un mago (magi) o de un hombre maléfico (malefici hominis), confiesen ustedes que han enderezado contra mí calumnias vanas (vanas calumnias), que también se caen. ${ }^{47}$

Tercera: "tiene en casa algo que venera religiosamente". Sus adversarios lo acusan — dice - de haber adquirido una estatui1la "para maleficios mágicos (ad magica maleficia) en un taller oculto, fabricada de madera rarísima... que a pesar de tener una figura burda y horrible de esqueleto, sin embargo, la venero con fervor (impendio colere)". ${ }^{48}$ Explica esta situación, aclarando que la estatuilla no es un esqueleto, sino una hermosa imagen de Mercurio, la cual describe mostrándola al público que asiste al juicio:

risueño es el rostro del dios, con cuánta gracia desciende el bozo en uno y otro lado de sus mejillas; cómo asoma en su cabeza el cabello rizado bajo el ala del sombrero, cuán graciosamente se destacan sobre sus sienes las dos alitas iguales. ${ }^{49}$

Mercurio, portador de los cantos mágicos (vector carminum), era un dios que se consideraba - lo dice el mismo Apuleyo-

\footnotetext{
${ }^{46}$ Apol., 43.

${ }^{47}$ Apol., 51.

${ }^{48}$ Apol., 61.

${ }^{49}$ Apol., 63.
} 
una de las principales divinidades invocadas en las ceremonias de los magos, junto con Venus, seductora del ánimo (illex animi), la Luna cómplice de las noches (noctium conscia) y Trivia, poderosa sobre los manes (manium potens). ${ }^{50}$ Confiesa que ha sido iniciado en varios misterios, y que es discípulo de Platón, para presentarse ante todos como sabio, filósofo y sacerdote y no como un vulgar mago.

La última acusación era verdaderamente grave, se trataba de los sacrificios nocturnos. En el desarrollo del juicio, sus acusadores presentaron una prueba: un testimonio escrito de un tal Junio Craso, aficionado a la bebida (studiosus bibendi), quien se dice que vendió dicho testimonio (dicitur testimonium istud vendisisse) y que, además, no asistió al tribunal. Apuleyo presenta aquí un ejemplo de la lectura de un testimonio sin la comparecencia del testigo. La acusación era ésta:

que yo solía celebrar sacrificios nocturnos (sacra nocturna) en su casa <de Junio Craso> en compañía de Apio Quinciano, un amigo mío que se hospedaba ahí por una renta (qui ibi mercede deversabatur). Craso... estaba en Alejandría, sin embargo, comprobó el hecho por el humo de la antorcha (taedae fumo) y las plumas de las aves (avium plumas). ${ }^{51}$

Alejandría estaba bastante lejos de Oea, donde sucedieron los supuestos sacrificios, Apuleyo se defiende al ridiculizarlo diciendo que desde Alejandría, entre banquetes, pudo ver y reconocer el humo de su hogar en Oea, "ha adivinado con su nariz el olor de su casa, ha vencido en finura de olfato a los perros y a los buitres". 52

Además de mostrarse aquí como prueba un testimonio escrito de un testigo ausente, se muestra otra figura jurídica, la del falso testimonio. Éste se castigaba de acuerdo con la lex

\footnotetext{
${ }^{50}$ Apol., 32.

${ }^{51}$ Apol., 57.

52 Idem.
} 
Cornelia de falsis, también llamada testamentaria, y la pena era el exilio o la relegación a una isla. Si por el falso testimonio alguien moría, el reo era juzgado por la lex Cornelia de sicariis et veneficiis. ${ }^{53}$

Los sacrificios ilícitos se hacían ocultamente, en la noche y con antorchas. ${ }^{54}$ Se hacían sacrificios de animales, por ejemplo, una paloma blanca atraía los favores de Afrodita; pero los más terribles eran los sacrificios humanos y los rituales de asesinatos, los cuales fueron prohibidos por dos legislaciones: el Senadoconsulto del 186 a. C. y la misma lex Cornelia de sicariis et veneficis. Dicho senadoconsulto se refería especialmente a los ritos de las Bacanales:

que ningún varón se inicie en los ritos dionisiacos, ni ciudadano romano, ni latino... Que las ceremonias no se celebren en oculto, ni en público ni en privado... 'se decreta que quienes contravinieran lo escrito serán reos de la pena capital'... haréis desaparecer las bacanales... salvo aquellas ceremonias autorizadas. ${ }^{55}$

Con relación a este crimen, Modestino se refiere a la pena de la lex Cornelia: "En virtud de un senadoconsulto se dispone que sea castigado con la pena de esta ley el que hubiera hecho o celebrado sacrificios ilícitos (mala sacrificia)" ${ }^{56}$

En época posterior a Apuleyo hay registro de constituciones imperiales que castigaban con penas muy severas las prácticas de magia. Se encuentran en dos códigos: el Justiniano y el Teodosiano, bajo el título "Acerca de los hechiceros, astrólogos y demás semejantes (De maleficis et mathematicis et

\footnotetext{
${ }^{53}$ Cf. Coll., 8, 2, 1; 8, 4, 1; PS., 5, 15, 5; D., 22, 5, 16.

${ }^{54} \mathrm{La}$ antorcha representaba la iniciación, como la que usa Psique para ver a Cupido, era un elemento esencial en el culto de Isis, también era un instrumento usados en la brujería. Cf. Ma. José Hidalgo, p. 226.

${ }^{55}$ Senadoconsulto de Bacchanalibus en Textos de Derecho Romano, coord. Rafael Domingo. El texto se encuentra en una tabla de mármol.

${ }^{56}$ D., $48,8,13$
} 
ceteris similibus)" ${ }^{57}$ En una ley de Constantino se lee, por ejemplo:

Aquel adivino (illo haruspice) que haya entrado a una casa ajena ha de ser quemado (concremendo)... y aquel (illo) que lo haya invitado por persuasión o gratificación ha de ser relegado a una isla con la confiscación de sus bienes (detruendo in insulam post ademptionem bonorum). ${ }^{58}$

Contra la doctrina de los persas, aquella que Apuleyo ensalzaba tanto, existe una constitución de Diocleciano en el Código Gregoriano:

nuevos prodigios... nacieron desde la nación persa (de Persica), enemiga nuestra, y debe temerse que... intenten infectar con sus malévolos venenos al pueblo romano... Ordenamos, pues, que los promotores y los principales... sean quemados con brillantes fuegos (flammeis ignibus exurantur)..., mandamos que los conformes con estas religiones sean castigados con la pena capital (capite puniri), y disponemos que sus bienes sean vindicados por el fisco (forum bona fisco nostro uindicari). Si algunas personas honorables... se convirtieran a una secta o a la doctrina de los persas (ad doctrinam Persarum)..., que sus patrimonios se agreguen al fisco (eorum patrimonia fisco nostro adsociari); y que ellos mismos también sean entregados a las minas... (ipsos quoque... metallis dari). ${ }^{59}$

En conclusión, las legislaciones que Apuleyo conoció sobre la magia, y que asimismo cita en su obra son: la ley de las XII Tablas y la lex Cornelia de sicariis et veneficiis. De acuerdo con su situación social le pudo haber correspondido la deportación a una isla con la confiscación de sus bienes y la pérdida

\footnotetext{
${ }^{57}$ Cod. Iust., 9, 18; Cod. Theod., 9, 16.

${ }^{58}$ Cod. Theod., 9, 16, 1 pr. La constitución es del año 319 d. C.

${ }^{59}$ Cf. Coll., 15, 3, 1. La constitución es del año 320, según Mommsen, este año es dudoso.
} 
de la ciudadanía romana. Por otra parte, este crimen de magia tanto en la ley de las XII Tablas como en las constituciones del siglo IV, de Constantino y Diocleciano, imponían penas tan severas como la horca, la hoguera, arrojo a las bestias o trabajos en las minas, en ocasiones sin distinción de la clase social.

Apuleyo, hábil orador, se defiende de una manera magistral, anulando prácticamente todas las acusaciones que sus adversarios interpusieron contra él, dejándolos en ridículo, como charlatanes e ignorantes. Se muestra ante el procónsul Claudio Máximo y ante todo el público que asistió al juicio, no como un mago, sino como un hombre culto, estudioso, interesado en la religión, en la filosofía y en la ciencia.

Este discurso judicial probablemente no se pronunció como ahora lo leemos, lo más seguro es que el autor lo preparó, después del juicio, para su publicación. Esta magnífica obra puede ser una fuente importante para el estudio de la filosofía, de la ciencia, de la retórica, de la historia de la magia, de la forma de vida en una provincia romana; pero, sobre todo, para el estudio del Derecho Romano, como aquí he tratado de demostrar.

\section{BIBLIOGRAFÍA}

San Agustín, La ciudad de Dios, trad. Lorenzo Riber, Barcelona, Alma Mater, 1953, vol. I.

AlBRECHT, Michael von, Historia de la literatura romana, Barcelona, Herder, 1999, t. II.

ApulÉE, Apologie-Florides, trad. de Paul Vallette, Paris, Les Belles Lettres, 1971.

Apuleio, La magia, trad. de Claudio Moreschini, Milano, Rizzoli (Biblioteca Universale Rizzoli), 1990.

Apuleius of Madauros, Pro se de magia (Apologia), edición de Vincent Hunink, J. C., Amsterdam, Gieben, Publisher, 1977.

Apuleyo, Apología o Discurso sobre la magia, trad. de Roberto Heredia, México, Universidad Nacional Autónoma de México (Bibliotheca Scriptorum Graecorum et Romanorum Mexicana), 2003. 
Apuleyo, Apología, Flórida, trad. de Santiago Segura Munguía Madrid, Gredos, 1980.

Berger, Adolf, Encyclopedic Dictionary of Roman law, Philadelphia, The American Philosophical Society, 1968.

Butler, H. E., “Apuleius, Apologia, c. 89”, $C R$, vol. 25, núm. 3, mayo 1911, pp. 72-73.

Comparación de leyes mosaicas y romanas (Collatio), 2a. ed., versión de Martha Elena Montemayor Aceves, México, Universidad Nacional Autónoma de México (Bibliotheca Iuridica Latina Mexicana), 2006.

DAREMBerg, Ch., ET AL., Dictionnaire des antiquités grecques et romaines, Verlagsanstalt, Graz, Akademische Druck, 1969.

"Digesta Iustiniani”, en Corpus Iuris Civilis, Theodor Mommsen (ed.), Dublín, Weidmannos, 1963, vol. I.

El Digesto de Justiniano, trad. Álvaro d'Ors et al., Pamplona, Editorial Aranzadi, 1968-1975, 3 vols.

GaYo, Instituciones, Fco. Hernández Tejero (coord.), Madrid, Editorial Civitas, 1985.

GuIllÉn, José, Vrbs Roma, vida y costumbre de los romanos, Salamanca, Ediciones Sígueme, 1981, t. 1 La vida privada.

Gutiérrez-Alviz, F., Diccionario de Derecho Romano, Madrid, Reus, 1976.

Helm, R., Pro se de magia liber (Apologia), Leipzig, Teubner, 1959.

HidAlgo, María José, "La magia y la religión en las obras de Apuleyo", Supplied by the British library-the world's knowledge, pp. 223-230.

“Ley de las XII Tablas", en Textos de Derecho Romano, coord. Rafael Domingo Navarra, Aranzadi, 2002.

Mommsen, Teodoro, Derecho penal romano, Bogotá, Editorial Temis, 1991.

D’Ors, Álvaro, Derecho Privado Romano, Pamplona, Ediciones Universidad de Navarra, 2004 (9a. ed.).

Novissimo Digesto Italiano, diretto da Antonio Azara e Ernesto Eula, vol. X, Torino, Editrice Torinese, 1964.

Padilla Sahagún, Gumesindo, Derecho Romano, México, McGraw-Hill, 2008 (4a. ed.).

PHARR, Clyde, "The interdiction of Magic in Roman Law", TaPhA, 1932, vol. 63, pp. 269-295.

Paulo, El libro $V$ de la Sentencias, tesis de maestría de Merecedes Fuentes, México, Universidad Nacional Autónoma de México, Facultad de Filosofía y Letras, 2006.

Pline L'Ancien, Histoire Naturelle, Paris, Les Belles Lettres, 1972, livre XVIII traduit par Henri Le Bonniec. 
Pline L'Ancien, Histoire Naturelle, Paris, Les Belles Lettres, 1962, livre XXVIII traduit par A. Ernout.

Reglas de Ulpiano, trad. Francisco Hernández Tejero, Madrid, Ministerio de Justicia y Consejo Superior de Investigaciones Científicas, 1946.

Rives, J. B., "Magic in the XII Tables Revisited", $C Q$, vol. 52, no. 1, 2002, pp. 270-290.

Villaseñor, Patricia, "Apuleyo, filósofo y mago", Acta Poética, 17, primavera de 1996, pp. 53-69. 